\section{Infrared Study of Reorientational Potential Barrier in Three Aliphatic Nitriles}

\author{
M. Penko, B. Borštnik, D. HadžI, and A. Ažman
}

Chemical Institute Boris Kidrič, Department of Chemistry, University Ljubljana, Yugoslavia

(Z. Naturforsch. 28 a, 547-548 [1973]; received 7 December 1972)

Several recent papers have emphasized the current interest in the study of infrared band shapes in condensed phases. The aim of this note is to report the temperature dependence of the half-widths of certain IR bands of succinonitrile, malononitrile and acetonitrile with primary interest in the elucidation of the mechanism influencing the half-width. Generally it is assumed that the main contributions are the vibrational or intrinsic $\left(\Delta W_{\mathrm{V}}\right)$ and the reorientational $\left(\Delta W_{\mathrm{r}}\right)$ relaxations. The separation of both contributions can be done by Raman spectroscopy ${ }^{1,2}$ but in our work we used the much simpler method due to RAKOv ${ }^{3}$. The half-width is written as:

$$
\Delta W=\Delta W_{\mathrm{v}}+\Delta W_{\mathrm{r}}
$$

and only $\Delta W_{\mathrm{r}}$ is a function of temperature $\Delta W_{\mathrm{r}} \sim \exp$ $(-\Delta E / k T)$ where $\Delta E$ is the activation energy.

All bands we have studied are free of overlap with others. The following bands were observed: succinonitrile ${ }^{4}: \mathrm{CH}_{2}$ rocking $\left(1002 \mathrm{~cm}^{-1}\right), \mathrm{C}-\mathrm{CN}$ stretching $\left(917 \mathrm{~cm}^{-1}\right)$ and $\mathrm{CH}_{2}$ rocking $\left(960 \mathrm{~cm}^{-1}\right)$; malononitrile ${ }^{5}: \mathrm{CH}_{2}$ rocking $\left(936 \mathrm{~cm}^{-1}\right), \mathrm{C}-\mathrm{N}$ stretching $\left(2270 \mathrm{~cm}^{-1}\right), \quad \mathrm{C}-\mathrm{C}$ antisymmetric stretching (983 $\left.\mathrm{cm}^{-1}\right)$ and $\mathrm{C}-\mathrm{C}$ symmetric stretching $\left(890 \mathrm{~cm}^{-1}\right)$; acetonitrile ${ }^{6}: \mathrm{C}-\mathrm{C}$ stretching $\left(919 \mathrm{~cm}^{-1}\right)$ and $\mathrm{CH}_{3}$ rocking $\left(1042 \mathrm{~cm}^{-1}\right)$.

The temperature dependence of the half-width was measured far below solidification of succinonitrile and acetonitrile because these two species have a plastic phase. The same was not possible for malononitrile because at the liquid-solid phase transition the bands split up.

In Figs. 1 and 2 the measured half-widths are presented. In succinonitrile the activation energy has the same value $(0.39 \mathrm{kcal} / \mathrm{mol})$ for all three observed bands. The dipole correlation functions connected with the measured bands have a similar temperature dependence. From this one can conclude that the reorientations about two axes (perpendicular to $\mathrm{C}-\mathrm{CN}$ stretch-

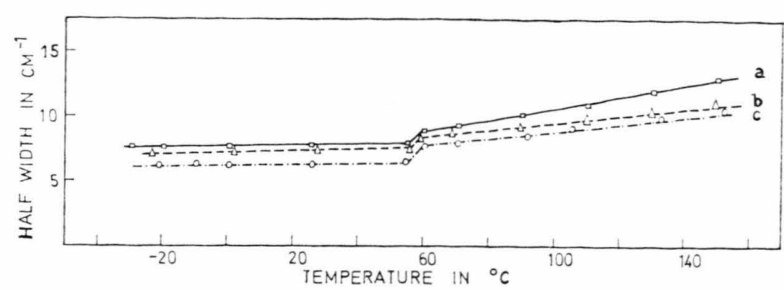

Fig. 1. Half-widths of succinonitrile: a $\left(917 \mathrm{~cm}^{-1}\right)$, b (1002 $\left.\mathrm{cm}^{-1}\right)$, c $\left(960 \mathrm{~cm}^{-1}\right)$.

ing and $\mathrm{CH}_{2}$ rocking) are isotropic. In malononitrile the activation energies for $\mathrm{C}-\mathrm{N}$ stretching, $\mathrm{C}-\mathrm{C}$ antisymmetric and symmetric stretching have a similar value $(0.4 \mathrm{kcal} / \mathrm{mol})$ while the activation energy for $\mathrm{CH}_{2}$ rocking $(0.98 \mathrm{kcal} / \mathrm{mol})$ is much higher. If the above mentioned separation [Eq. (1)] is correct then the half-widths of the $\mathrm{C}-\mathrm{C}$ symmetric stretching and the $\mathrm{CH}_{2}$ rocking bands have to be of the same order. The reason why this is not so may be in the temperature dependence of $\Delta W_{\mathrm{v}}$. The results with acetonitrile are of particular interest. The separation of the vibrational modes into $\mathrm{C}-\mathrm{C}$ stretching and $\mathrm{CH}_{3}$ rocking is much more pronounced than in the previous two examples ${ }^{6}$. The dipole moment changes have better defined orientations. The dipole autocorrelation function of $\mathrm{C}-\mathrm{C}$ stretching is influenced by the overall molecular reorientation. The dipole autocorrelation function of $\mathrm{CH}_{3}$ rocking is influenced by two contributions from an overall reorientation and from the internal $\mathrm{CH}_{3}$ group rotation. The separation into these two contributions can be done by supposing that both reorientations are independent. The measured dipole autocorrelation function $C_{\mathrm{m}}$ of $\mathrm{CH}_{3}$ rocking is then given by

$$
C_{\mathrm{m}}=C_{\mathrm{i}} \cdot C_{0}
$$

with $C_{\mathrm{i}}$ the autocorrelation function of the $\mathrm{CH}_{3}$ group and $C_{0}$ the autocorrelation function of the overall molecular reorientation taken to be the autocorrelation function of $\mathrm{C}-\mathrm{C}$ stretching. In accordance with Eq. (2) the measured bands were Fourier inverted to yield the dipole autocorrelation functions. The measurements done in $\mathrm{CCl}_{4}$ solution were within experimental error

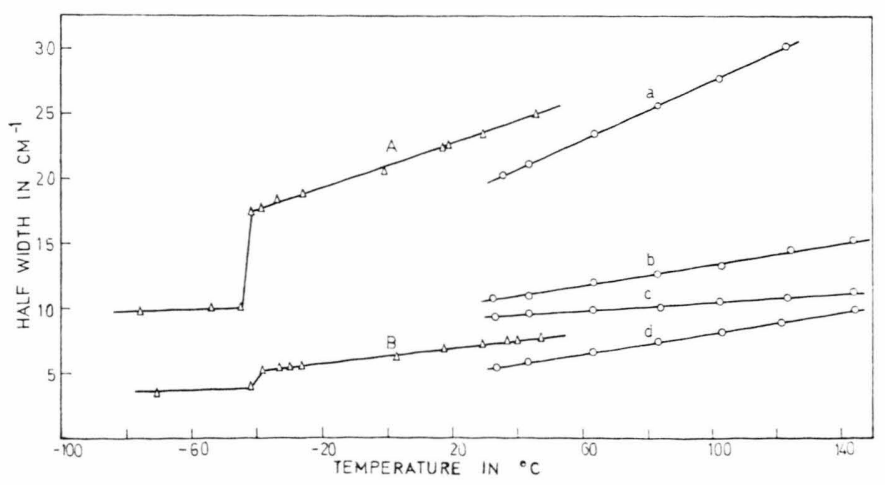

$\begin{array}{ll}\text { Malononitrile: } & \text { a }\left(936 \mathrm{~cm}^{-1}\right), \\ & \text { b }\left(2270 \mathrm{~cm}^{-1}\right), \\ & \text { c }\left(983 \mathrm{~cm}^{-1}\right), \\ \text { Acetonitrile: } & \text { d }\left(890 \mathrm{~cm}^{-1}\right) ; \\ & \text { A }\left(1042 \mathrm{~cm}^{-1}\right), \\ & \text { B }\left(919 \mathrm{~cm}^{-1}\right) .\end{array}$


equal to that done on the pure sample. This is in accordance with the observation in Ref. ${ }^{7}$ and therefore the cross correlation functions are neglected. The values of $\Delta E$ are $0.75 \mathrm{kcal} / \mathrm{mol}$ for $\mathrm{C}-\mathrm{C}$ stretching and 1.20 $\mathrm{kcal} / \mathrm{mol}$ for $\mathrm{CH}_{3}$ rocking and the correction with Eq. (2) gives the value $0.54 \mathrm{kcal} / \mathrm{mol}$. The dipole autocorrelation function of $\mathrm{CH}_{3}$ rocking is changing with

1 S. Bratož and E. Maréchal, Phys. Rev. A 4, 1078 [1971]. 2 F. J. Bartoli and T. A. Litovitz, J. Chem. Phys. 56, 404 [1972].

3 A. V. Rakov, Opt. Spectrosc. 7, 202 [1959].

4 T. Fujiyama, K. Tokumaru, and T. Shimanouchi, Spectrochim. Acta 20, 415 [1964]. rotation of the $\mathrm{CH}_{3}$ group around the $\mathrm{C}_{3}$ axis. The value $0.54 \mathrm{kcal} / \mathrm{mol}$ represents then the potential barrier for the rotation of the $\mathrm{CH}_{3}$ group.

\section{Acknowledgement}

This work was supported by Boris Kidrič Fund.

5 T. Fujiyama and T. Shimanouchi, Spectrochim. Acta 20, 829 [1964].

6 I. Nakagawa and T. Shimanouchi, Spectrochim. Acta 18, 513 [1962].

7 J. YARWOOD, Spectroscopy Lett. 5, 193 [1972]. 